\title{
ESTUDAR E VIVER A HISTÓRIA: UM OLHAR COMPLEXO SOBRE O ESTUDO DO PASSADO
}

\author{
Waldy Luiz Lau Filho ${ }^{1}$ \\ Nize Maria Campos Pellanda ${ }^{2}$
}

Resumo: O estudo das teorias da complexidade foi de fundamental importância para desencadear uma pesquisa sobre o processo de cognição e de subjetivação dos alunos e professores participantes de uma vivência denominada Aulão de História - Dia Mundial do Rock (AH-DMR), ambiente pedagógico organizado em uma escola de educação básica no estado do Rio Grande do sul desde o ano de 2008. Tendo como ponto de partida o entrelaçamento da perspectiva da complexidade (MORIN, 2013), da Biologia da Cognição (MATURANA e VARELA, 2011), do estudo das narrativas (GONÇALVES, 2002) e da vivência AH-DMR em si, concebida como um ambiente de aprendizagem ruidoso, essa reflexão teve o objetivo de problematizar em que medida estudar História poderia significar viver a História. Essa pesquisa utilizou uma metodologia predominantemente qualitativa e foi fundamentada na existência de uma relação de dinamicidade entre a vivência AH-DMR e o processo de cognição e de subjetivação de seus participantes. De uma forma geral, esse estudo permitiu-me perceber a História como uma ação emocionada e corporalizada sobre o que conhecemos como passado, ao ressignificar o devir histórico e, assim, ampliar o estudo da História sob a ótica da complexidade. Além do mais, operei nessa pesquisa com a percepção de que cada participante do ambiente de aprendizagem AHDMR, ao estudar o passado e, ao mesmo tempo, vivenciar esse passado, não apenas elaborou uma narrativa sobre esse passado, mas, sobretudo, situou-se a si próprio na História e assumiu também sua autoria sobre a História.

Palavras-chave: História. Educação. Complexidade. Ensino de História.

${ }^{1}$ Graduado em História pela Universidade Federal do Rio Grande do Sul - UFRGS, Mestrade em Educação pela jiversidade de Santa Cruz do Sul. Coordenador Pedagógico da escola básica e professor de História do Ensino Médio do légio Mauá. E-mail: professorwaldy@gmail.com

2 Graduada em História (UFRGS), mestrado em História da Cultura (PUCRS), doutorado em Educação (UFRGS) com utorado-sanduiche na M.U. (OHIO-USA). Estágio de Pós-doutoramento na Universidade do Minho (PORTUGAL). Atualmente ? Estágio Sênior de pesquisa na Universidade do Minho. É docente e pesquisadora da UNISC onde atua nos Programas de s-Graduação. 


\title{
STUDYING AND LIVING HISTORY: A COMPLEX LOOK AT THE STUDY OF THE
}

\section{PAST}

\begin{abstract}
The study of complexity theories was of fundamental importance to trigger a research on the process of cognition and subjectivation of students and teachers participating in an experience called History Class - World Day of Rock (AH-DMR), a pedagogical environment organized in an elementary school in the state of Rio Grande do Sul since 2008. As a starting point for the intertwining of the complexity perspective (MORIN, 2013), the Biology of Cognition (MATURANA and VARELA, 2011), the narratives studies (GONÇALVES, 2002) and AH-DMR experience itself, conceived as a noisy learning environment, this reflection had the objective of problematizing to what extent studying History could mean living History. This research used a predominantly qualitative methodology and was based on the existence of a dynamical relationship between AH-DMR experience and the process of cognition and subjectivation of its participants. In a general way, this study allowed me to perceive History as an emotionalized and embodied action on what we know as the past, by re-signifying the historical becoming and thus expanding the study of History from the point of view of complexity. In addition, I operated in this research with the perception that each participant in the AH-DMR learning environment, studying the past and at the same time experiencing that past, not only elaborated a narrative about it but, above all, was him/herself in History and also assumed his/her authorship over History.
\end{abstract}

Keywords: History. Education. Complexity. Teaching History.

\section{ESTUDIAR Y VIVIR LA HISTORIA: UNA MIRADA COMPLEJA SOBRE EL ESTUDIO DEL PASADO}

Resumen: El estudio de las teorias de la complejidad fue de fundamental importancia para desencadenar una investigación sobre el proceso de cognición y de subjetivación de los alumnos y profesores participantes de una vivencia denominada Classe de Historia - Día Mundial del Rock (AH-DMR), ambiente pedagógico organizado en una escuela de educación básica en el estado de Rio Grande do Sul desde el año 2008. Con el punto de partida del entrelazamiento de la perspectiva de la complejidad (MORIN, 2013), de la Biología de la Cognición (MATURANA y VARELA, 2011), del estudio de las narrativas (GONÇALVES, 2002) y de la vivencia AH-DMR en sí, concebida como un ambiente de aprendizaje ruidoso, esa reflexión tuvo el objetivo de problematizar en qué medida estudiar Historia podría significar vivir la Historia. Esta investigación utilizó una metodología predominantemente cualitativa y fue fundamentada en la existencia de una relación de dinamicidad entre la vivencia $\mathrm{AH}-$ DMR y el proceso de cognición y de subjetivación de sus participantes. En general, este estudio me permitió percibir la historia como una acción emocionada y corporalizada sobre lo que conocemos como pasado, al resignificar el devenir histórico y, así, ampliar el estudio de la historia bajo la óptica de la complejidad. Además, operé en esa investigación con la percepción de que cada participante del ambiente de aprendizaje AH-DMR, al estudiar el pasado $\mathrm{y}$, al mismo tiempo, vivenciar ese pasado, no sólo elaboró una narrativa sobre el mismo, pero, sobre todo, a sí mismo en la Historia y asumió también su autoría sobre la Historia.

Palabras clave: Historia. Educación. Complejidad. Enseñanza de Historia 


\section{Introdução}

O ponto de partida para a realização desse trabalho de pesquisa foi a trajetória de uma vivência denominada Aulão de História - Dia Mundial do Rock (AH-DMR), ambiente pedagógico organizado em uma escola de educação básica no estado do Rio Grande do Sul desde o ano de 2008.

Ao longo destes anos e de suas respectivas apresentações, o modelo proposto para o AH-DMR foi semelhante: a partir de uma temática central, professores de História e de diferentes áreas do conhecimento e alunos do Ensino Médio são desafiados a elaborar conjuntamente uma aula de História, a qual integrará elementos como teatro, música, vídeos, poesia e dança. Esta atividade é tradicionalmente apresentada para o público da escola, num primeiro momento e, na sequência, em um evento aberto a toda a comunidade.

Para esse estudo, mais especificamente, o objetivo consiste em olhar para o AH-DMR na perspectiva da complexidade, entendendo-o como um ambiente de aprendizagem ruidoso. E, nesse contexto, estudar como se constituem os processos de cognição e subjetivação dos alunos e professores participantes da vivência. Sob esse prisma, em que medida estudar História significaria viver a História?

\section{A Complexidade e a Biologia da Cognição}

Essa pesquisa foi fundamentada na existência de uma relação de dinamicidade entre a vivência AH-DMR e o processo de cognição e de subjetivação dos alunos e professores participantes da mesma. Para Neves (1996), esse vínculo entre signo e significado, conhecimento e fenômeno, sempre depende do arcabouço de interpretação empregado pelo pesquisador, que lhe serve de visão de mundo e de referencial. Por sua vez, "[...] este arcabouço pode servir como base para estabelecer caminhos de pesquisa quantitativa e delimitação do tema, de forma tal que os esforços de cunho qualitativo e quantitativo podem se complementar" (NEVES, 1996, p. 2).

O referencial que utilizei para a constituição dessa pesquisa foi a perspectiva da complexidade. De acordo com Morin, Almeida e Carvalho (2013, p. 56), em contraposição ao paradigma da simplificação, torna-se significativo elaborar um 
novo paradigma, “[...] um paradigma de complexidade que, ao mesmo tempo disjunte e associe, que conceba os niveis de emergência da realidade sem reduzilos às unidades elementares e às leis gerais”. O desafio trazido pela complexidade é duplo: religar o que anteriormente era considerado separado e interagir as certezas com a incerteza.

Nessa busca da perspectiva da complexidade a Biologia da Cognição (2011) desempenha um importante papel, especialmente quando afirma que a linguagem e a cognição são conectadas inextrincavelmente e, por isso, estão presentes em todas as nossas atividades. Para Maturana (2002, p. 18), o humano se constitui no entrelaçamento do emocional com o racional, "O racional se constitui nas coerências operacionais dos sistemas argumentativos que construímos na linguagem, para defender ou justificar nossas ações”.

Assim, na Biologia da Cognição, a linguagem é compreendida "[...] como um fenômeno próprio do ser vivo, ou associado ao ser vivo em termos de símbolos" (MATURANA, 2002, p. 58). A linguagem tem suas características e se constitui e se acopla ao viver e ao modo de viver do humano.

Maturana (1999) ressalta também a importância da linguagem na constituição do humano, como elemento de transformação do homem e da própria linguagem. Nesses termos, “[...] nada do que fazemos ou pensamos é trivial nem irrelevante, porque tudo o que fazemos tem consequências no domínio das mudanças estruturais a que pertencemos" (MATURANA, 2002, p. 65).

Interagindo com e pela linguagem, provocam-se mudanças tanto na linguagem como no humano. E, estabelecendo-se relações com os outros através da linguagem, uma multiplicidade de narrativas se torna possivel, considerando que as narrativas estão presentes em vários contextos da vida cotidiana.

As narrativas são formas de significado que operam em um contexto dialógico situando-se no espaço da interindividualidade. São elas que dão sentido à existência voltando à experiência comum, já que, para o ser humano, dar sentido é, sobretudo, voltar ao comum (GONÇALVES, 2002, p. 22).

A base teórica que fundamenta essa pesquisa compreende que, toda pessoa, independentemente de ser ou não leitora e/ou escritora de obras literárias, ao permitir-se a vivência complexa da narrativa, tem a consciência de sua 
multipotencialidade. "Ter uma atitude narrativa significa, deste modo, estar aberto à exploração da complexidade" (GONÇALVES, 2002, p. 32). Conforme o referido autor, a narrativa constitui uma matriz fundamental de construção do conhecimento ao impor significado à textura da experiência diária.

A importância da narrativa está no seu potencial de autoconstituição. Ao refletir sobre si, cada sujeito, ao ler ou escrever as narrativas, está atribuindo significados para a sua própria vida, e, dessa forma, complexificando-se. Esse processo ocorre de maneira única e pessoal, onde cada sujeito se complexifica observando a si mesmo em relação aos outros e com o mundo. Ao mesmo tempo, todo esse percurso inclui o próprio pesquisador no processo de subjetivação e complexificação.

Nós, cientistas, fazemos ciência como observadores explicando o que observamos. Como observadores, somos seres humanos. Nós, seres humanos, já nos encontramos na situação de observadores observando quando começamos a observar nosso observar em nossa tentativa de descrever e explicar o que fazemos. Isto é, nós já nos encontramos na linguagem, fazendo distinções na linguagem, quando começamos a refletir na linguagem sobre o que fazemos, e como fazemos o que fazemos ao operar como animais linguajantes. (MATURANA, 2014, p. 134).

Portanto, na perspectiva da complexidade, o pesquisador "[...] não é mais alguém fora do sistema a observar uma realidade da qual não faz parte, mas um sujeito que precisa dar conta de sua própria ação ao operar" (BOETTCHER; PELLANDA, 2010, p. 34). Trata-se do "observador implicado", como denominou Maturana (2014), que pensa sobre o seu pensar e, ao explicitar seu ponto de vista sobre o que se propõe a estudar, ingressa num processo de crescente complexificação.

\section{Participantes da Pesquisa}

A presente pesquisa foi realizada ao longo de cinco meses de um mesmo ano letivo, no período de março a julho, em uma escola de Educação Básica privada de um município do estado do RS. A escola atende 1600 alunos, da Educação Infantil ao Ensino Médio, e possui aproximadamente 100 professores.

O ambiente de aprendizagem AH-DMR envolveu aproximadamente 70 (setenta) pessoas, entre alunos e professores da escola. Aceitaram participar da 
pesquisa 12 (doze) alunos e 03 (três) professores de Ensino Médio, organizados da seguinte forma: 02 (dois) alunos da primeira série do Ensino Médio, 04 (quatro) alunos da segunda série do Ensino Médio e 06 (seis) alunos da terceira série do Ensino Médio, ao lado de 03 (três) professores de diferentes componentes curriculares do Ensino Médio. Os professores participantes da pesquisa foram, respectivamente, um professor de Geografia, uma professora de História e um professor de Filosofia.

Os alunos e professores participantes da pesquisa, mediante seu aceite, foram convidados a elaborar narrativas por escrito sobre o seu processo de cognição e subjetivação desencadeado pela vivência AH-DMR. Cumpre ressaltar que, tanto os alunos quanto os professores participantes da pesquisa envolveram-se neste processo de duas maneiras. Primeiro, ao participar de todo o percurso de elaboração e apresentação da vivência AH-DMR. Em segundo lugar, ao refletir sobre esta caminhada e elaborar as suas narrativas.

Tabela 1 - Participantes da Pesquisa

\begin{tabular}{|c|c|}
\hline CODIFICAÇÃO & TERMINOLOGIA \\
\hline A01 & Aluno $1^{\text {a }}$ série ensino médio 1 \\
\hline A02 & Aluno $1^{\text {a }}$ série ensino médio 2 \\
\hline A03 & Aluno $2^{\text {a }}$ série ensino médio 1 \\
\hline A04 & Aluno $2^{\text {a }}$ série ensino médio 2 \\
\hline A05 & Aluno $2^{\text {a }}$ série ensino médio 3 \\
\hline A06 & Aluno $2^{\text {a }}$ série ensino médio 4 \\
\hline A07 & Aluno $3^{\text {a }}$ série ensino médio 1 \\
\hline A08 & Aluno $3^{\text {a }}$ série ensino médio 2 \\
\hline A09 & Aluno $3^{\text {a }}$ série ensino médio 3 \\
\hline A10 & Aluno $3^{\text {a }}$ série ensino médio 4 \\
\hline A11 & Aluno $3^{\text {a }}$ série ensino médio 5 \\
\hline A12 & Aluno $3^{\text {a }}$ série ensino médio 6 \\
\hline P01 & Professor ensino médio 1 \\
\hline P02 & Professor ensino médio 2 \\
\hline P03 & Professor ensino médio 3 \\
\hline
\end{tabular}

Fonte: Adaptado pelo autor.

\section{Procedimentos de geração das emergências}

As narrativas fazem parte do nosso cotidiano e, ao mesmo tempo, permitem às pessoas constantemente criarem e recriarem a sua própria história, com 
autonomia. "Ao abrir-se narrativamente à complexidade da experiência, o sujeito toma consciência de sua multipotencialidade" (GONÇALVES, 2002, p. 32).

Esse constante criar e recriar a própria história, de forma autônoma, é o caráter autopoiético que emerge das narrativas. As narrativas possibilitam interagir com o meio, mudando estruturalmente seus autores e o próprio meio. Segundo Moraes (2003), trata-se de coexistir com o meio e com a sua comunidade com a qual coexiste biológica, emocional, mental e espiritualmente.

Mas, coexiste em seu viver de maneira autônoma, em função da
dinâmica que, de fato, o constitui. Isto nos leva a perceber que um
sistema somente existe como organismo vivo enquanto interage com
o ambiente. Ao relacionar-se com o meio, desencadeia mudanças
em suas próprias estruturas. Assim, a condição necessária e
suficiente para que um sistema vivo exista é a sua autopoiese, a sua
capacidade de autoprodução e de criação de si mesmo (MORAES,
2003 , p. 88).

Para a geração e registro das emergências alunos e professores participantes foram convidados a produzir uma descrição por escrito de suas experiências de subjetivação e de cognição durante o percurso do ambiente de aprendizagem AHDMR. O convite foi feito por meio de uma conversa com os interessados em participar da pesquisa no mesmo encontro em que se estabeleceu coletivamente o tema do ambiente de aprendizagem. O tema escolhido especificamente para esta vivência foi a relação entre o rock e as múltiplas formas de amor, com o título "Os Brutos também Amam”.

Durante esse encontro de conversação, os participantes da pesquisa foram desafiados a tecer três narrativas em formato de texto, as quais poderiam ser carta, relato, redação, texto acadêmico etc. A escolha do formato textual para a narrativa caberia ao próprio autor. Acordou-se nessa oportunidade que as narrativas, uma vez elaboradas, seriam enviadas ao pesquisador através de mensagem eletrônica (e-mail).

Nesse contexto, interessou-me observar como os alunos e professores participantes da vivência se constituíram com sua subjetividade e como se relacionaram com o estudo da História a partir dessas perturbações. 


\section{Procedimentos para o Tratamento das Emergências}

Com o propósito de estabelecer uma estratégia para o estudo das narrativas geradas a partir da vivência AH-DMR, trouxe para essa pesquisa a utilização de alguns marcadores, instrumentos operatórios que oferecem determinadas referências e dão vida às emergências.

Como essa proposta de investigação se insere na perspectiva da complexidade, cumpre enfatizar que compreendo o tema da pesquisa como uma rede de relações que pode ser modificada constantemente, em função das vivências e mudanças produzidas nos sujeitos participantes da mesma, o que confere a toda investigação um caráter de imprevisibilidade. Assim, os marcadores se constituem em instrumentos operatórios que possibilitam o acompanhamento do fluxo do viver, o qual é indissociável do processo de conhecer.

Os marcadores selecionados para esse trabalho de pesquisa foram os seguintes: processo autopoiético, acoplamento estrutural, complexificação pelo ruido e viver em ato. Todos esses marcadores guardam uma profunda relação entre si, sendo que as narrativas têm o potencial de trazer um ou mais de um desses marcadores, uma vez que os autores das narrativas, ao pensarem sobre as mesmas, podem fazer emergir toda uma matriz de "organização de significados" (GONÇALVES, 2002).

O primeiro marcador, o processo autopoiético, foi escolhido em função de sua importância dentro dessa perspectiva teórica. Autopoiese significa autocriação, autoprodução. "Esta teoria considera que a conservação da organização de um sistema vivo, estruturalmente acoplado ao meio onde existe, é condição sine qua non de sua existência" (MORAES, 2003, p. 85). Portanto, para que um sistema vivo exista, a condição necessária e a sua autopoiese remete "[...] à sua capacidade de autoprodução e de criação de si mesmo" (MORAES, 2003, p. 88).

A opção pelo estudo das narrativas de alunos e de professores participantes da pesquisa possibilitaria observar aspectos autopoiéticos do humano, uma vez que, ao escreverem sobre suas vivências no ambiente de aprendizagem AH-DMR, alunos e professores também estariam escrevendo sobre suas próprias histórias de vida e, dessa forma, estariam se reconfigurando. 
O marcador acoplamento estrutural está fortemente conectado ao processo autopoiético. Para Moraes (2003), um sistema é vivo por estar em processo de contínua mudança estrutural, derivada a partir das possibilidades de conservação de suas condições de adaptação ao meio, com o qual se relaciona em seu viver. "É vivo porque interage constantemente com o meio ambiente e, a partir de suas interações, acontecem mudanças estruturais congruentes com as mudanças também estruturais que ocorrem no próprio meio (MORAES, 2003, p. 88).

O pensamento com o qual opero parte do princípio de que as narrativas trazem a possibilidade de fazer emergir a percepção autopoiética em um processo vital contínuo, em que o sujeito, ao se relacionar com o meio, percebe o quanto ele transforma ao mesmo tempo em que desencadeia mudanças em suas próprias estruturas.

Por sua vez, o marcador complexificação pelo ruído se comunica com a concepção de acoplamento estrutural, tendo em vista que dependemos do ambiente para o exercício de nossa própria autonomia. A partir do momento em que alunos e professores participantes da pesquisa iniciaram o percurso de interação com o ambiente de aprendizagem AH-DMR, desde as suas primeiras etapas estiveram expostos ao que Atlan (1992) denominou "ruído", isto é, um conjunto de elementos externos que disparam perturbações internas nos sujeitos, de onde se potencializa o processo de auto-organização e a sua própria complexificação.

Todos esses marcadores convergem para o marcador viver em ato. Nessa pesquisa, considera-se que a vivência da história no ambiente de aprendizagem AH-DMR é o próprio processo cognitivo. "A característica central desse processo cognitivo especial é a experiência da autopercepção - estar consciente não apenas do próprio ambiente, mas também de si mesmo" (CAPRA; LUISI, 2014, p. 320).

\section{O Fluxo da Pesquisa}

Para a geração das emergências a partir das narrativas, foi encaminhado aos participantes da pesquisa um conjunto de sete perguntas, agrupadas em três 
narrativas distintas. Especificamente nessa reflexão, apresento elementos que emergiram a partir de duas perguntas, formuladas em diferentes momentos.

No início do processo de elaboração da primeira narrativa, a seguinte pergunta foi elaborada e enviada a todos os participantes da pesquisa: Como me sinto frente ao desafio de participar da constituição conjunta da vivência AH-DMR?

Em relação a essa questão, a maior parte dos alunos consultados utilizou expressões como "honrado", "lisonjeado", "feliz", "orgulhoso". O aluno A01, por exemplo, escreveu sobre se sentir "[...] um pouco nervoso, assustado $e$ preocupado", mas, ao mesmo tempo, satisfeito por ter sido convidado para participar do projeto. Algo semelhante foi trazido pelos professores participantes da pesquisa, mostrando uma mistura de apreensão pelo desafio apresentado com a satisfação em fazer parte desse projeto.

As narrativas evidenciaram um conjunto de distintas emoções em relação à vivência AH-DMR e às expectativas iniciais de seus participantes. Entendo ser esse um aspecto muito importante, uma vez que, para Maturana (2002, p. 23), “[...] não é a razão o que nos leva à ação, mas a emoção". Para a Biologia da Cognição, o ato de educar é permanente tanto na criança quanto no adulto, sendo que a mesma ocorre na convivência com o outro.

O amor é a emoção que constitui o domínio de ações em que nossas interações recorrentes com o outro fazem do outro um legítimo outro na convivência. As interações recorrentes no amor ampliam e estabilizam a convivência; as interações recorrentes na agressão interferem e rompem a convivência. (MATURANA, 2002, p. 22).

Dentro dessa percepção, a cognição tem uma relação muito forte e direta com o ambiente. A aprendizagem está ligada a fatores internos do sujeito, mas também está conectada aos fatores que o circundam. "Um ambiente que valorize determinadas habilidades e competências influencia na maneira como elas se desenvolvem" (MORAES, 2003, p. 95).

Como observador implicado, na primeira pergunta formulada nessa pesquisa duas narrativas chamaram muito a minha atenção. A primeira delas, elaborada por A11, parte do olhar de um aluno que participou da vivência AH-DMR na condição de músico. 
Tocar junto dos professores é uma das coisas que eu mais gosto, pois cada um colabora da sua forma com ideias distintas na música e não tem quem saiba mais. É estranho o fato de seus colegas de música serem na verdade seus professores. Na hora do "Aulão", vendo o teatro cheio, percebe-se o quão importante é o evento e a gigante responsabilidade que se tem em executar a sua função da melhor forma. Além disso, a experiência adquirida com outros músicos participantes é muito significativa, assim como eles também aprendem comigo. (A11).

Em sua primeira narrativa, A11 aponta para uma das características centrais da vivência AH-DMR, qual seja a constituição conjunta desse espaço por alunos e professores, em que todos se transformam em “colegas de música” (A11). Ressalto, também, a importância de um discente se dar conta que, nessa atividade, todos podem aprender com todos, inclusive alunos e seus professores. É possivel sentir sua satisfação em poder partilhar saberes sem correr o risco de ser repreendido, num ambiente de diálogo e cooperação. Percebo nesse aspecto uma aproximação do que Valente (2003, p. 15) denomina escola viva. "É viva porque o aluno e a escola devem estar acoplados estruturalmente e, para isto, educadores e aprendizes devem se colocar por inteiro nesta relação”.

Assim, enfatizo nessa narrativa a manifestação da importância das interações com o meio, contribuindo para a construção de sentido, o que ao longo desse trabalho é apresentado como "viver em ato". Colocar-se por inteiro, implica experiências significativas para todos, mesmo que, aparentemente, isso possa parecer "estranho" (A11). Estudantes aprendendo com professores, “[...] assim como eles também aprendem comigo" (A11).

Da mesma forma, destaco nesse relato a percepção do estudante A11 sobre um outro modelo pedagógico, que é complexo, porque permite uma interação entre todos esses elementos. Para Pellanda (2009), “[...] o processo de ensinoaprendizagem é sempre um processo que articula todas as dimensões do ser. Nessa perspectiva, o ensino de forma solitária torna-se um processo ilusório, pois conhecer é sempre conexão" (PELLANDA, 2009, p. 43).

De acordo com o sujeito A11, a vivência AH-DMR possibilita uma aprendizagem diferente da História, a qual é vivida através e a partir da música. Conforme Bustamante (2011, p. 183-184), “[...] a narrativa histórica encontra sentido quando serve para orientar os sujeitos de uma comunidade na condução 
de seu existir, fazendo com que os sujeitos entendam as condições de seu lugar diante dos demais".

A segunda narrativa que destaco foi inicialmente elaborada pelo sujeito A09. Para esse aluno, por sua vez, a vivência AH-DMR traz uma significativa oportunidade.

Senti-me orgulhoso em participar e desafiado em escrever um roteiro para ser apresentado para toda a sociedade. O Aulão de História é um local onde podemos debater os acontecimentos de diferentes formas, como a música, teatro e vídeos que nos fazem pensar em vários acontecimentos, que às vezes nem nos damos conta que ocorreram com tanta intensidade. (A09).

Apresento esse excerto por acreditar que a história de um indivíduo é a história da constituição de seus conhecimentos. O conhecimento e a experiência são inseparáveis. Sob a perspectiva autopoiética, aprender significa transformarse em coerência com o emocionar. Significa reconhecer suas emoções, seus sentimentos e afetos, “[...] já que o autoconhecimento e o conhecimento de sua história, de seu corpo, de suas emoções são inseparáveis do conhecimento de sua realidade e de seu contexto" (MORAES, 2003, p. 158).

Entendo que a fala do sujeito A09, quando menciona "tanta intensidade", refere-se justamente a uma releitura pessoal e emocionada de acontecimentos históricos, o que acaba atribuindo ao mesmo toda uma nova rede de significados. A esse respeito, acrescenta Moraes (2003, p. 158), “[...] as nossas maneiras de ser, de ver e de perceber o mundo, de viver/conviver, de perceber ou não as contradições e injustiças condicionam as realizações e o conhecimento que construímos".

Após a realização do ambiente de aprendizagem AH-DMR, alunos e professores foram convidados nessa etapa da pesquisa a elaborar suas narrativas a partir da seguinte questão: O que significa para mim vivenciar a História no $A H$ $D M R ?$

Para os professores participantes da pesquisa, o caráter interativo do ambiente pedagógico AH-DMR, percebido tanto no diálogo entre alunos e professores nas etapas preparatórias, como nas trocas ocorridas com a plateia na vivência em si, foi um aspecto importante destacado em suas narrativas. Sob a 
minha ótica, a primeira pista sobre o que para esse grupo de professores pesquisados significaria "vivenciar a história", manifestou-se na narrativa de P03.

Para o sujeito P03, “[...] com certeza, em algum momento, cada pessoa lembrou de uma vivência que já teve”. Segundo o ponto de vista desse professor, a história de cada pessoa é marcada por diferentes elementos, como fatos importantes, músicas, comerciais de televisão. Reunir alguns desses elementos nesse ambiente pedagógico a partir da temática do amor permitiu um momento que "nos fez pensar" (P03).

Destaco esse ponto da narrativa expressa por P03, uma vez que ele me remete ao pensamento de Espinosa, para quem conhecer é ser afetado. "Espinosa põe em questão a unidade socrática entre conhecer e agir, uma vez que o compreender por si só não basta para originar uma ação. Só mesmo o ser afetado traz consigo um feito" (HORNÄK, 2010, p. 198). Ao atrelar afetividade e conhecimento, Espinosa postula que é preciso cultivar a maior quantidade possivel de afecções, fazendo assim do próprio conhecimento um acontecimento afetivo. "Só no agir surge a possibilidade de se desenvolver completamente e realizar tendo em vista a potência de atividade essencial do homem" (HORNÄK, 2010, p. 165-166).

Sob esse prisma, fatos importantes, como músicas ou comerciais de televisão, seriam os elementos externos que provocariam nos participantes da vivência as afecções que, por sua vez, desencadeariam nesses sujeitos um processo de complexificação. "Vivenciar a história", assim, seria um processo pessoal de resgatar essas marcas, essas afecções, de acordo com o historial de vivências próprio de cada sujeito.

A segunda pista sobre o que seria "vivenciar a história" foi expressa na narrativa do sujeito P02 que, por sua vez, manifestou a seguinte reflexão a esse respeito: “[...] Muito interessante foi que o projeto permitiu-me pensar a história - à la Ítalo Calvino - como um passado que não terminou de dizer aquilo que tinha para dizer" (P02).

Encontro nesse excerto um dos aspectos centrais trazidos por essa pesquisa, a percepção de uma diferença entre as concepções de passado e história e o caráter de vida que existe nesse olhar emocionado sobre o passado. Como 
recomendava Febvre (1985), “[...] para fazer história, virem resolutamente às costas ao passado e antes de mais vivam. Envolvam-se na vida" (FEBVRE, 1985, p. 40).

A concepção da história "[...] como um passado que não terminou de dizer aquilo que tinha para dizer" (P02) remeteu-me ao pensamento do Nietzsche, um dos importantes referenciais para essa pesquisa. Estudioso da obra de Nietzsche, Julião (2006, p. 235) escreve que esse filósofo distingue três atitudes fundamentais da História:

[...] a atitude do erudito, antiquária; a atitude crítica e a atitude da História monumental. A primeira corresponde a um tipo humano conservador e venerador de uma humanidade que vive inteiramente da tradição e que dela recebe a transmissão de suas tarefas; a vida é essencialmente recordação e comemoração. A História crítica, pelo contrário, corresponde a uma atitude fundamental que, em primeiro lugar, se abre para o presente e faz dele padrão das coisas passadas, conduz a História ao fórum presente. A História monumental corresponde a uma atitude que se projeta para o futuro. Quando a vida se propõe a tarefas grandiosas, revela também interesse por tais audaciosos projetos no passado. Só na decidida vontade de futuro se revela também o que há de futuro em todo o passado. Se o programa vital, o projeto de vida para o futuro se afunda, a acumulação do saber histórico torna-se um fardo, um perigo para a vida; o homem aprende então na História apenas a designação, a inutilidade de todos os projetos; a vida vazia de impulsos criadores para um futuro próprio refugia-se no passado, procura esquecer o seu próprio vazio na plenitude estranha da vida vivida.

Essa abordagem é significativa para a interpretação nietzschiana da existência à luz das estruturas do tempo, das dimensões passado, presente e futuro. "Estas não são como os quadros no interior dos quais a existência se produz simplesmente como qualquer outra coisa; são antes horizontes abertos pela existência e, na verdade, horizontes de maneiras diferentes" (JULIÃO, 2006, p. 236).

Nesse sentido, esse passado que se projeta para o futuro é um pouco de um "passado que não terminou de dizer aquilo que tinha para dizer" (P02). E que, talvez, nunca permita terminar de dizer o que tinha para dizer, devido ao caráter vivo desse devir histórico.

Por sua vez, as narrativas dos alunos participantes da pesquisa, em relação à temática do que significava para eles vivenciar a história no $A H-D M R$, 
expressaram novamente um sentimento de alegria e satisfação pessoal em participar desse ambiente pedagógico. Para o sujeito A06, por exemplo, tratou-se de "[...] uma experiência sem igual", enquanto que para o sujeito A01 significou “[...] uma experiência de aprendizado de forma mais leve”. O sujeito A03, por sua vez, expressou que o processo em si de participação na vivência foi "maravilhoso", e que esse envolvimento "significa muito, já que contam com a minha participação no projeto" (A03). Mais uma vez emergia das narrativas a importância que os alunos atribuem a um real envolvimento nas atividades escolares, diferentemente de uma postura que ainda os submete a uma atitude de passividade.

As narrativas que apresentaram uma maior densidade ao tratar do significado de "vivenciar a História" foram as seguintes:

[...] representa dar vida à história na forma de arte, mostrando de forma simples e descontraída o quanto o passado pode nos ensinar. (A04).

[...] com este projeto sou estimulada a pesquisar, estudar, criar e atuar sobre história e ainda expandir conhecimentos em politica, economia e outras diversas matérias importantes e necessárias para os acontecimentos atuais, inclusive sobre o amor. (A05).

No Aulão de História vivenciamos a História de uma forma diferente e podemos compartilhar com o público esta experiência, saímos da sala de aula, vamos para o palco, após termos pesquisado sobre determinada época ou um fato histórico. (A07).

Para mim, vivenciar a história no Aulão de História significa compreender que ela é feita de um conjunto de coisas e fatos, assim como no Aulão, uns traduzem a história tocando, outros encenando, e outros na forma de palauras narradas mesmo. (A11).

Para o sujeito A04, "vivenciar a História" significaria "[...] dar vida à História na forma de arte”. Na mesma direção aponta o sujeito A05, quando afirma que a vivência AH-DMR permite “[...] pesquisar, estudar, criar e atuar sobre história”.

Percebo nessas duas narrativas a compreensão de que "vivenciar a história no $A H-D M R$ ” foi algo possivel para esses alunos, em função da utilização de recursos artísticos. O teatro e a dança seriam alguns dos caminhos que permitiriam a esses estudantes "[...] dar vida à História" (A04) e "criar e atuar sobre História” (A05). 
Aspecto semelhante surgiu na narrativa do sujeito A07, quando esse afirmou que no AH-DMR "[...] vivenciamos a História de uma forma diferente". Mais do que isso, o espaço do palco torna possivel "compartilhar com o público esta experiência" (A07). Por sua vez, o sujeito A11, ao referir-se ao momento do palco, afirma que "[...] uns traduzem a história tocando, outros encenando, e outros na forma de palavras narradas" (A11).

Assim, a História deixaria de ser vista apenas como o estudo do passado, mas também como uma ação efetiva e corporalizada sobre o passado, resgatando o que Varela (1994) entende por enação. "Enação implica o desenvolvimento ou o pôr em prática de uma linha de vida. Evoca a imagem de seres vivos a traçarem caminhos históricos através de suas próprias dinâmicas e das dos meios ambientes a que estão estruturalmente acoplados" (THOMPSON, 2007, p. 255).

É como o traçar de um caminho que se faz caminhando, assim como dois parceiros numa dança, onde produzem os movimentos um do outro, organismo e ambiente determinam-se um ao outro através do seu acoplamento estrutural.

De acordo com Rancière $(2011$, p. 35), “[...] para que o tempo seja resgatado, é preciso que ele seja um puro presente, um princípio de copresença dos sujeitos históricos". Segundo o autor, é preciso que os sujeitos históricos se assemelhem ao seu tempo, ou seja, com o princípio da copresença. Além do mais, acrescenta que, para que advenha à História algo de eternidade, é necessário contar com seres que carregam o seu tempo em seus corpos, em todos os seus modos de ser e de fazer.

\section{Considerações Finais}

O estudo das teorias da complexidade foi de fundamental importância para desencadear essa pesquisa sobre o processo de cognição e de subjetivação dos alunos e professores participantes da vivência AH-DMR.

Pude perceber através de diferentes manifestações o significativo papel que a vivência AH-DMR desempenhou para esse grupo de alunos e professores, no sentido de proporcionar um reencantamento com o ato de aprender e a constituição de um novo olhar sobre o papel que a instituição escola ocupa em suas vidas. Igualmente, observei em suas narrativas a emergência da 
indissociabilidade entre o ato de conhecer e o fluxo do viver, o que também se traduziu em recorrentes referências de alunos e de professores em relação a assumir a autoria de suas vidas e sobre o seu processo de aprendizagem.

Minha contribuição para esse debate consiste não somente em problematizar concepções tradicionais de educação e de História, mas, a partir da perspectiva da complexidade, repensar a História. Conforme Nunes (1996, p. 12), é necessário superar a ideia de um estudo da História que tem apresentado como eixo o ensino do passado pelo passado, um estudo sem vinculação com o contexto da vida real de alunos e professores que, “[...] como sujeitos históricos e sociais, raras vezes são levados em conta quando da elaboração da maioria das propostas programáticas e metodológicas que sustentam o ensino da História”.

Esse estudo permitiu-me perceber a História como uma ação emocionada e corporalizada sobre o que denominamos de passado, ressignificando o devir histórico e, assim, ampliando o estudo da História sob a ótica da complexidade. Além do mais, operei nessa pesquisa com a percepção de que cada participante do ambiente de aprendizagem AH-DMR, ao estudar o passado e, ao mesmo tempo, vivenciar esse passado, não apenas elaborou uma narrativa sobre o mesmo, mas, sobretudo, situou-se a si próprio na História e assumiu também sua autoria sobre a História.

Nesta direção, postulo que o estudo da vivência AH-DMR, tendo como ponto de partida a perspectiva da complexidade (MORIN, 2013), a Biologia da Cognição (MATURANA; VARELA, 2011) e o estudo das narrativas (GONÇALVES, 2002), abre um rico campo de investigação, sobretudo para o processo de ensino e aprendizagem de História na Educação Básica. Esse estudo abre vários caminhos a serem trilhados e muitos atos a serem ainda vividos.

\section{Referências}

ATLAN, Henri. Entre o Cristal e a Fumaça: ensaio sobre a organização do ser vivo. Rio de Janeiro: Jorge Zahar Editora, 1992.

BOETTCHER, D. M.; PELlandA, N. M. C. (Org.). Viwências Autopoieticas. Santa Cruz do Sul: EDUNISC, 2010.

BUSTAMANTE, Aarón Grageda. História, Desconstrucionismo e Relativismo: notas para uma reflexão contemporânea. In: SALOMON, Marlon (Org). História, Verdade e Tempo. Chapecó (SC): Argos, 2011. p. 155-184. 
CAPRA, Fritjof; LUISI, P. L. A visão sistêmica da vida: uma concepção unificada e suas implicações filosóficas, políticas, sociais e econômicas. São Paulo: Cultrix, 2014.

FEBVRE, Lucien. Combates pela História. 2. ed. Lisboa: Editorial Presença, 1985.

GONCSALVES, Óscar F. Psicoterapia cognitiva narrativa. Manual de terapia breve. Bilbao: Desclêe de Brouwer, 2002.

HORNÄK, Sara. Espinosa e Vermeer: imanência na filosofia e na pintura. São Paulo: Paulus, 2010.

JULIÃO, José Nicolao. Nietzsche e a Interpretação Niilista da História. In: GUIDO, H.; SAHD, L. F.N. (Org.). Tempo e História no pensamento ocidental. Ijuí: Ed. Unijuí, 2006. p. 231-244.

MATURANA, Humberto. Emoções e linguagem na educação e na política. Belo Horizonte: Ed. UFMG, 2002.

MATURANA, Humberto. Cognição, ciência e vida cotidiana. 2. ed. Belo Horizonte: Ed. UFMG, 2014.

MATURANA, Humberto. Transformación em la convivência. Santiago: Dólmen Ediciones, 1999.

MATURANA, Humberto R.; VARELA, Francisco J. A árvore do conhecimento: as bases biológicas da compreensão humana. São Paulo: Palas Athena, 2011.

MORAES, Maria Cândida. Educar na biologia do amor e da solidariedade. Petrópolis: Vozes, 2003.

MORIN, Edgar; ALMEIDA, M. C.; CARVALHO, E. A. (Org.). Educação e complexidade: os sete saberes e outros ensaios. 6. ed. São Paulo: Cortez, 2013.

NEVES, José Luís. Pesquisa Qualitativa - Características, Usos e Possibilidades. Caderno de Pesquisas em Administração, São Paulo, v. 1, n. 3, p. 1-5, 2. sem., 1996.

NUNES, Silma do Carmo. Concepções de mundo no ensino da História. Campinas: Papirus Editora, 1996.

PELLANDA, Nize Maria Campos. Maturana \& a Educação. Belo Horizonte: Autêntica Editora, 2009.

RANCIĖRE, Jacques. O conceito de anacronismo e a verdade do historiador. In: SALOMON, Marlon (Org.). História, Verdade e Tempo. Chapecó (SC): Argos, 2011. p. 21-49.

THOMPSON, Evan. A mente na vida. Biologia, Fenomenologia e Ciências da Mente. Lisboa: Instituto Piaget, 2007.

VALENTE, José Armando. Prefácio. In: MORAES, Maria Cândida. Educar na biologia do amore da solidariedade. Petrópolis: Vozes, 2003.

VARELA, Francisco. Conhecer, As Ciências Cognitivas, Tendências e Perspectivas. Lisboa: Instituto Piaget, 1994. 